\title{
Rectal indomethacin versus intraperitoneal lidocaine for analgesia after laparoscopic cholecystectomy
}

\section{${ }^{\text {a} G a d ~ S a y e d ~ G a d ~, ~}{ }^{a}$ Hatem Saber Ali}

\section{${ }^{a}$ Department of Anaesthesia, ICU, and Pain Management, Faculty of Medicine, South Valley University, Qena, Egypt}

\section{Abstract}

Background: Visceral and shoulder pain are among the most frequent reported pain after laparoscopic cholecystectomy (LC).

Objectives: To investigate the effectiveness and clinical value of rectal indomecthacin and intraperitoneal lidocaine for treating pain after laparoscopic cholecystectomy.

Patients and methods: In Qena university hospital, this prospective randomized comparative study was conducted, 80 patients were scheduled to elective laparoscopic cholecystectomy. Group intraperitoneal "IP" lidocaine (40 patients) received $200 \mathrm{ml}$ saline containing $200 \mathrm{mg} 2 \%$ lidocaine immediately after pneumoperitoneum, the total solution was sprayed on the upper surface of the liver, right subdiaphragmatic space and around the cholecystectomy site. Group indomethacin (40 patients) received two $100 \mathrm{mg}$ indomethacin rectal suppositories 2 hours prior to surgery.

Results: VAS score was significantly lower in indomethacine group ( $p$ value $=0.03$ )over the 24 hours postoperative. The postoperative pethidine requirements were significant lower in group indomethacin mean $(34 \pm 11.4 \mathrm{mg})$. Postoperative nausea and vomiting were less in group indomethacin with no statistically significant difference.

Conclusion: preoperative rectal indomethacin suppositories decrease postoperative pain scores and analgesics requirements without producing side effects comparing to IP lidocaine in LC.

Clinical trail .gov . ID:NCT04964180

Keywords: Indomethacine , Laparoscopy; postoperative pain; lidocaine, intraperitoneal.

\section{Introduction}

The most frequent reported pain after laparoscopic cholecystectomy (LC) are visceral and shoulder pain, the patients complain of parietal pain more than visceral pain in laparotomy procedures Shoulder pain is reduced by intraperitoneal lidocaine (IP) after laparoscopy(Honca et al .,2014).
In a Previous studies patients

premedicated with a prostaglandin synthetase inhibitor reduced the postoperative pain score (Zhang et al .2017).

After thoracic and major abdominal surgery indomethacin with narcotics, have been used for postoperative analgesia. However

NSAID's have been recommended for

Copyright: (c) Gad et al. (2022) Immediate open access to its content on the principle that making research freely available to the public supports a greater global exchange of knowledge. Users have the right to Read, download, copy, distribute, print or share link to 
chronic pain management (White, 2005).

There were many treatment modalities for management of postoperative pain after LC, but none of them have demonstrated consistent efficacy (Yang et al., 2014;Mitra et al.,2012).

Postoperative pain was reduced by IP administration of a local anaesthetic. The aim of this prospective comparative study was to compare the efficacy of rectal indomethacin and IP lidocaine administration in LC patients.

\section{Patients and methods}

This prospective randomized comparative study was conducted in Qena University Hospitals after written informed consent was taken from every patient participating in the study after getting approval from the Ethical Committee of Qena University Hospitals, Qena, Egypt in period between May 2020 to May 2021,eighty patients was scheduled to elective laparoscopic cholecystectomy, divided into two groups randomly using closed envelop method. Group IP lidocaine(40 patients ) received $200 \mathrm{ml}$ saline containing $200 \mathrm{mg} 2 \%$ lidocaine immediately after abdominal cO2 insufflation (pneumoperitoneum) the surgeon sprayed the total solution on the upper surface of the liver under the right subdiaphragmatic space and around the cholecystectomy site, all patients were maintained in trendelenberg position.

$$
\text { Group indomethacin }
$$

patients) received two $100 \mathrm{mg}$ indomethacin rectal suppositories 2 hours prior to surgery .ASA physical status $1-2$

Patients 18-60 years old were included to the study ..Exclusion criteria were using or allergic to non-steroidal anti inflammatory drugs 
(NSAIDs) or aspirin and history of serious hepatic disease, renal or gastrointestinal disease, a bleeding disorder, body mass index BMI $<18$ or $>30 \mathrm{~m}^{2} / \mathrm{kg}$, history of abdominal surgery, a chronic pain disorder other than gallbladder disease or allergy to lidocaine.

Standard anaesthesia surgical techniques were used in all .All patients were operated on by selective endotracheal intubation mechanically ventilated with volume controlled mechanical ventilation using (DatexOhmeda A 7100 GE Healthcare,

Finland). The anaesthetics administered were propofol $1 \%$ $2 \mathrm{mg} / \mathrm{kg}$,nalbuphine $0.2 \mathrm{mg} / \mathrm{kg}$ and atracurium0.5mg/kg. Anaesthesia was maintained by isofluranein oxygen $\left(\mathrm{FiO}_{2}=1\right)$ during the whole anaesthesia period.

The hemodynamic parameters electrocardiogram, heart rate (HR), non-invasive blood pressure and pulse oximetry $\quad\left(\mathrm{SaO}_{2}\right) \quad$ peripheral temperature and end tidal $\mathrm{CO} 2\left(\mathrm{ETCO}_{2}\right)$ were continuously monitored(GE Healthcare USA).A nasogastric tube was inserted and the patient was placed in aprior position for laparoscopic surgery. Local anaesthetics with $1 \%$ lidocaine for the skin incision was standardised to all patients. At the end of surgery the abdomen was deflated of $\mathrm{CO}_{2}$ prior to termination of the procedure.

Neuromuscular blockade was then reversed with neostigmine $(0.04 \mathrm{mg} / \mathrm{kg}) \quad$ and atropine $(0.01 \mathrm{mg} / \mathrm{kg})$. Patients were transferred to the recovery area. The post operative nursing staff, unaware of the patient's group, recorded visual analogue score VAS at fixed intervals (a standard 10-cm VAS was used, where one end of the scale represented no pain $(0 \mathrm{~cm})$, and the other end the most severe pain imaginable $(10 \mathrm{~cm})$, the distance in centimetres being taken 
as the pain score),i.e., immediately postoperative, at 1, 2, 4,6, 8, 12 and 24 hours post-operatively and whenever the patient complained of pain. IV pethidine injection $25-50 \mathrm{mg}$ was given as rescue analgesic whenever the patient experienced pain $\geq$ to 5 VAS(our primary outcomes) .

The dose and Frequency of postoperative opioids injection in $24 \mathrm{~h}$ were recorded obtained from the nurses report forms and patient records on the patients' check list.

Postoperative side effects were our secondary outcomes.

\section{Statistically analysis}

In order to calculates the sample size we use the VAS score postoperative among the two group, with a p-value of 0.05 and a power of $80 \%$,we need
40 patients for each group, 80 patients for this study were required.

VAS score were compared using the Mann Whitney U test. A Pvalue of $<0.05$ considered significant, analysis of variance is used for Pethidine requirements between the two groups with repeated measures at each time interval. For the side effects were compared using chi-square test .all data were performed by SPSS version 21 .

\section{Results}

A total of 80patients presented for laparoscopic cholecystectomy were enrolled in this study. 40 in lidocaine group, 40 patients in indomethacin group There was no significant difference between groups regarding the age, gender, weight and duration of anaesthesia (Table 1). 
Gad et al (2022)

SVU-IJMS, 5(1):114-125

Table 1.Patients demographic data.

\begin{tabular}{|l|l|l|l|}
\hline Data & $\begin{array}{c}\text { Lidocaine group } \\
\mathbf{n = 4 0}\end{array}$ & $\begin{array}{c}\text { Indomethacin group } \\
\mathbf{n = 4 0}\end{array}$ & P value \\
\hline Age (years) & $38 \pm 4.3$ & $40 \pm 3.8$ & 0.13 \\
\hline Female/male(n) & $28 / 12$ & $23 / 17$ & 0.61 \\
\hline Weight(kg) & $64 \pm 12$ & $59 \pm 13$ & 0.43 \\
\hline $\begin{array}{l}\text { Duration of } \\
\text { anesthesia(min) }\end{array}$ & $46.25 \pm 13$ & $41.56 \pm 11$ & 0.23 \\
\hline
\end{tabular}

Data are presented as mean \pm SD

$*$ Significant $\mathrm{p}$ value $<0.05$

VAS score has been evaluated at regular time after surgery, there was

a statistical significant difference of between both groups, VAS score were consistently lower in indomethacine group $(\mathrm{p}$ value $=0.03) . \mathrm{In}$ both groups, the severity of pain gradually diminished over the 24 hours postoperative (Fig.1).

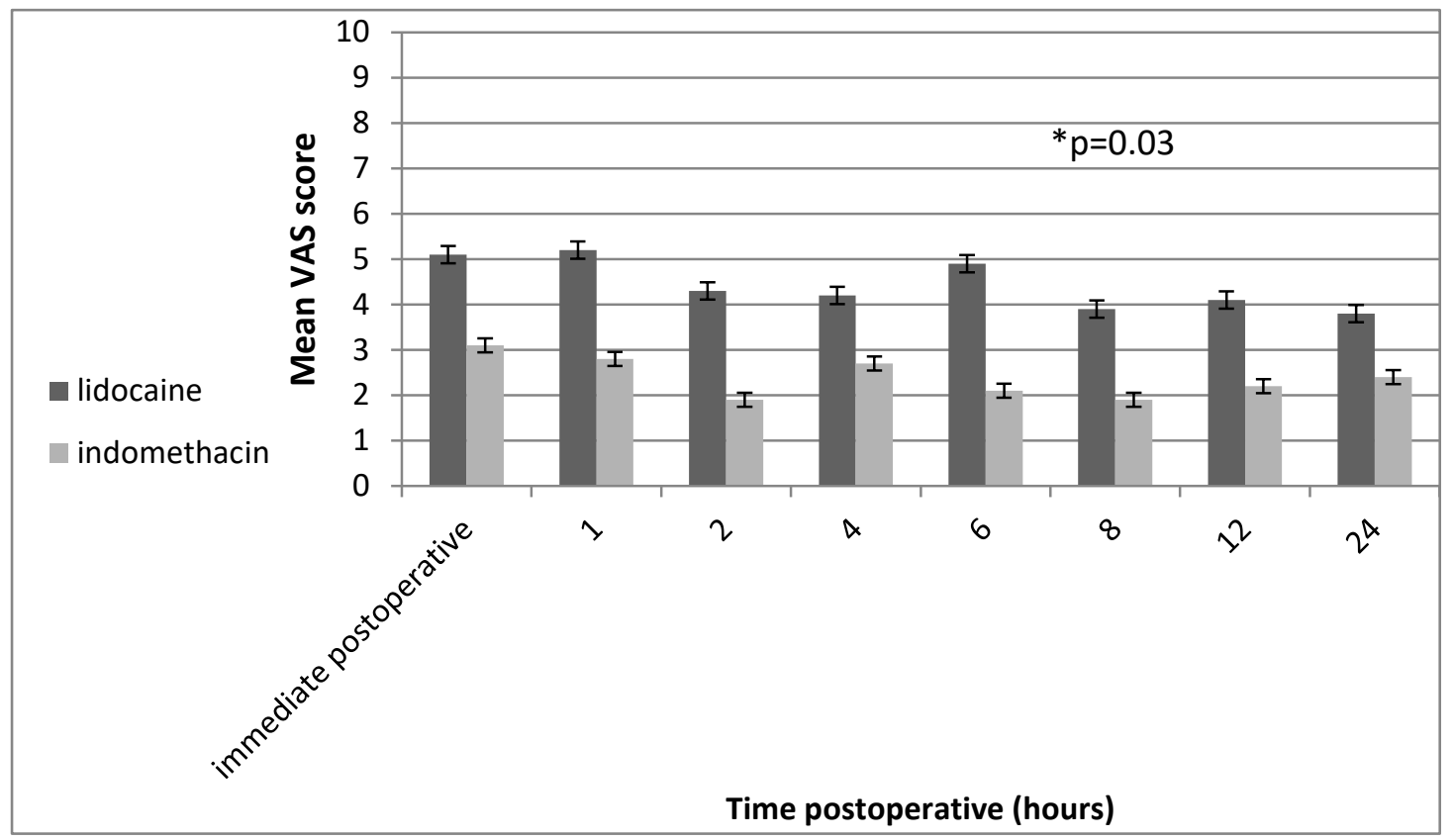

Fig.1. Mean VAS scores postoperative.

*Significant $\mathrm{p}$ value $<0.05$

Over the first 24 hour requirements were significant lower in postoperative the pethidine group indomethacin mean $(34 \pm 11.4$ 
$\mathrm{mg})$ comparison to group lidocaine mean $(42 \pm 12.5) \mathrm{p}$ value $<0.05$.figure 2

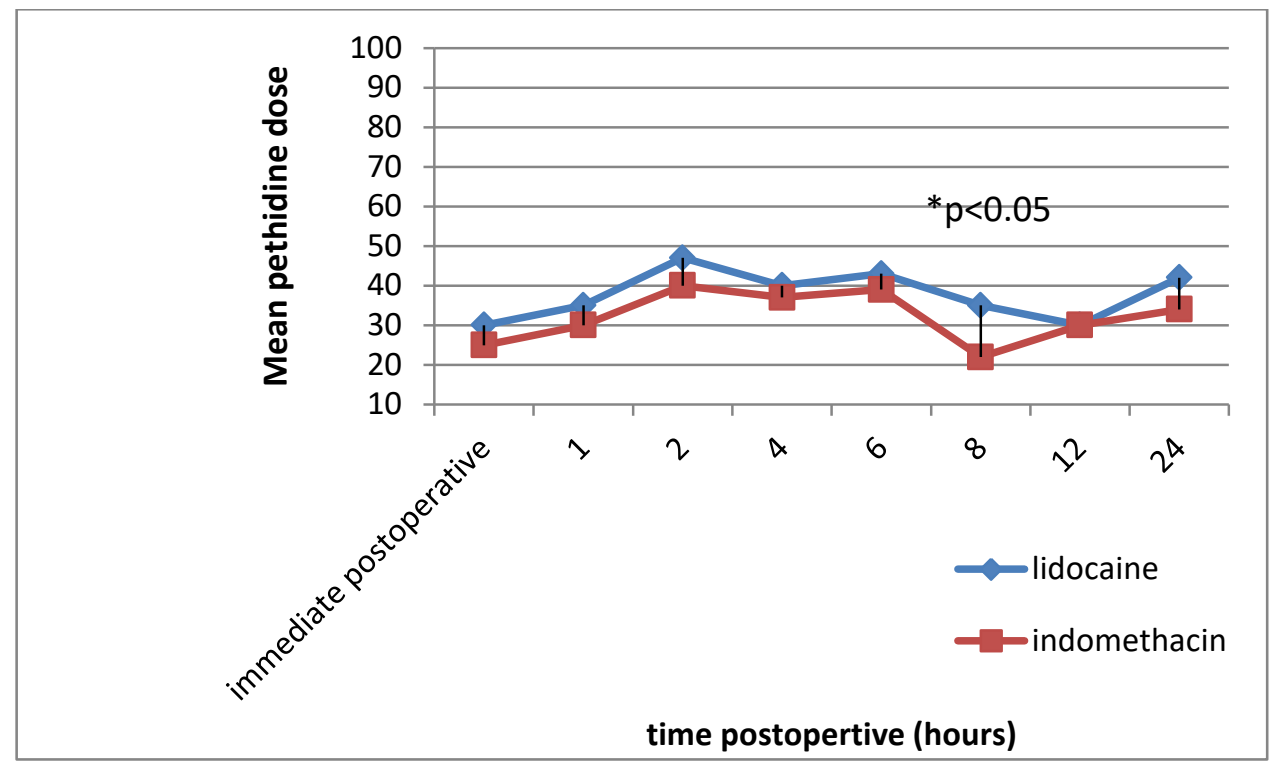

Fig.2. Postoperative pethidine requirements .

$*$ Significant $\mathrm{p}$ value $<0.05$

The mean time of pain after surgery started in lidocaine group $46 \pm 13.20 \mathrm{~min}$,indomethacin group $53 \pm 11.23 \quad \min \quad$ with statistically significant difference $(\mathrm{p}$ value $=0.01$ ).on the other hand there was no significant difference in the first time pethidine dose required (Table.2).

Table 2: Pain starting time after surgery and Pethidine required first time.

\begin{tabular}{|l|l|l|l|}
\hline Data & $\begin{array}{c}\text { Lidocaine group } \\
\mathbf{n = 4 0}\end{array}$ & $\begin{array}{c}\text { Indomethacin group } \\
\mathbf{n = 4 0}\end{array}$ & P value \\
\hline $\begin{array}{l}\text { Pain starting first } \\
\text { time (min) }\end{array}$ & $46 \pm 13.20$ & $53 \pm 11.23$ & $0.03^{*}$ \\
\hline $\begin{array}{l}\text { Pethidine } \\
\text { required first } \\
\text { time(min) }\end{array}$ & $51 \pm 8.30$ & $53 \pm 10.20$ & 0.15 \\
\hline
\end{tabular}

Significant $p$ value $<0.05$

Postoperative nausea and group indomethacin , but this trend was vomiting, were less frequently noted in not statistically significant (Table.3). 
Table 3. Incidence of postoperative side effects

\begin{tabular}{|l|l|l|}
\hline Side effect & \multicolumn{1}{|c|}{$\begin{array}{c}\text { Lidocaine group } \\
\mathbf{n = 4 0}\end{array}$} & $\begin{array}{c}\text { Indomethacin group } \\
\mathbf{n = 4 0}\end{array}$ \\
\hline Nausea & $12 \%$ & $7 \%$ \\
\hline Heartburn & $4 \%$ & $4 \%$ \\
\hline Vomiting & $10 \%$ & $5 \%$ \\
\hline Abdominal pain & $27 \%$ & $20 \%$ \\
\hline *Lidocaine related & 0 & 0 \\
\hline
\end{tabular}

*Blurred vision, hearing problems, dizziness, peripheral paraesthesia, itchinguncontrolled muscle contraction, convulsions, headache, hypotension, and bradycardia were lidocaine-related side effects . ${ }^{*}$ Significant $p$ value $<0.05$.

\section{Discussion}

LC has many advantages compare to open cholecystectomy, still the patients experiences postoperative moderate pain requiring opioids analgesic use.( Ali et al.,2020; Li et al.,2018; Ebrahimifard and Nooraei,2013). Somatic, visceral and shoulder tip pain all reported in after LC surgery.(Cianciet al.,2020; Tulgar et al.,2018; Protic et al .,2017)

At our hospital, indomethacin suppositories and IP lidocaine had been used in laparoscopic cholecystectomy to decrease postoperative opioid requirements in those patients .We studied a doubleblind comparative study to examine this assumption opioid- sparing effect. Indication of Lidocaine is used for regional anaesthesia ,antiarrthymia and analgesia for neuropathic and central pain(Tremont-Lukats et al.,2005) and postoperative pain.(Yousefshahi et al.,2017) 
Indomethacin inhibits the enzyme cyclooxygenase, blocking the production of prostaglandins that may enhance the analgesia effect of narcotic(Burian and Geisslinger, 2005)

In this study the effect of 2 hours preoperative indomethacin has been investigated as it is a widely used in reducing postoperative pain and opioid requirement after orthopaedic and major abdominal surgery.(Nielsen,2018; Bahar et al.,2010), two hours preoperatively of $200 \mathrm{mg}$ of rectal indomethacin induce the optimum peak plasma concentration and prostaglandin inhibition according to its pharmacokinetic profiles, we also didn`t report any side effect with this dose (bleeding tendency regarding inhibition of platelet aggregation), this is the maximum daily dose without significant side-effects.(Fokunang et al.,2018).
In this study we used IP lidocaine irrigation solution on the upper surface of the liver under the right subdiaphragmatic space and around the cholecystectomy site ,the mean VAS score 24 hours postoperative was $3.9 \pm 1.9$ as another study compared two different methods for LA IPdelivery duringLC, with a control group of patients receiving the same treatment, it reported that subperitoneal diaphragm injections of LA decreased postoperative pain and shortened recovery room stays(Roberts et al.,2011), as post-LC pain most probably somatic in nature.(Roberts et al.,2011)

In the current study purpose of pre-emptive analgesia in both groups was achieved, also in indomethacine group had a significant difference compare to IP lidocaine (VAS 5.1 \pm 1.04 lidocaine group, 3.1 \pm 1.2 indomethacin group) immediate postoperative. 
Another study reported the using of IP instillation of LA in addition to LA infiltration had significantly reducing the intensity of postoperative pain in a synergistic fashion (Khan et al.,2012).

Our study are in consistent with a study which reported the effect of IP LA as an analgesic in patients undergoing LC and its beneficial effects on postoperative abdominal, visceral, and shoulder pain.

\section{(Barczyński et al .,2006)}

The pethidine dose over the first 24 hours average $(34 \pm 11.4 \mathrm{mg})$ postoperative was lower in the indomethacin group compare to lidocaine group $(42 \pm 12.5) \quad \mathrm{p}$ value $<0.05$.

In our study IP lidocaine group received $200 \mathrm{ml}$ saline containing 200 mg $2 \%$ lidocaine immediately after abdominal $\mathrm{CO} 2$ insufflations as the intraperitoneal irrigation with lidocaine local anaesthetic solution may reduce humoral agent such as histamine and vasoactive polypeptide and carbon dioxide residual absorption which are implicated in the genesis of postoperative pain, also the onset and duration of block depend on total dose of local anaesthetic.(Choi et al .,2015) However, the high $\mathrm{CO} 2$ pressure insufflations with the mixing local anaesthetic are important for neural blockade. (Mumba et al.,2017).

Consistent to our results a study reported after open cholecystectomy $54 \%$ reduction in opioid requirement in the first 72 hoursfor the indomethacin group.(Bahar et al.,2010)

In a previous study reviewed that in lower and upper abdominal surgery NSAID reduce the postoperative opioid use by a $20-35 \%$ compared to placebo groups (Chang et al.,2020)

The current study we detected postoperative nausea which continued 
more than six hours, the incidence of nausea was $7 \%$ in the indomethacin group and $12 \%$ in the lidocaine group with no significant difference, decrease incidence of nausea in indomethacin group this may be duo to decrease pethidine requirements, postoperative pain and early recovery of gastrointestinal motility. Also there was many other factors influence the

\section{Conclusion}

According to our study results the use of preoperative rectal indomethacin suppositories reduces postoperative pain scores and opioid requirements without producing side effects in LC .

\section{Acknowledgement}

The authors would like to thank the nursing staff of general surgery department for their help with data collection during the study. incidence of postoperative nausea and vomiting.(Pierre and Whelan,2013).

The limitation of our study is that, there is no control group, the study result may not be used for ather surgical procedures because they are conducted only in LC, also the sample size relatively small to detect the effects and side effects of IP lidocaine and rectal indomethacin.

The main advantage of rectal indomethacin is that it is an applicable and easily method compared with IP instillation.

Conflict of interest The authors declare that they have no conflict of interest 


\section{References}

Ali BH, Hameed AZ, Isa RJ.(2020). Comparative Study of Dexamethasone Versus Ondansetron as Adjuvants to the Intra-Peritoneal Irrigation of Bupivacaine for Reducing the Postoperative Pain in Patients Undergoing Elective Laparoscopic Cholecystectomy. Systematic Reviews in Pharmacy.;11(12):463-8.

Bahar MM, Jangjoo A, Soltani E, Armand M, Mozaffari S.(2010) Effect of preoperative rectal indomethacin on postoperative pain reduction after open cholecystectomy. Journal of PeriAnesthesia Nursing. Feb 1;25(1):7-10.

Barczyński M, Konturek A, Herman RM.(2006) Superiority of preemptive analgesia with intraperitoneal instillation of bupivacaine before rather than after the creation of pneumoperitoneum for laparoscopic cholecystectomy: a randomized, double-blind, placebo-controlled study. Surgical Endoscopy And Other Interventional Techniques. Jul;20(7):1088-93.

Burian M, Geisslinger G.(2005). COX-dependent mechanisms involved in the antinociceptive action of NSAIDs at central and peripheral sites. Pharmacology \& therapeutics. Aug 1;107(2):139-54.

Chang RW, Tompkins DM, Cohn SM. (2020)Are NSAIDs Safe? Assessing the Risk-Benefit Profile of Nonsteroidal Anti-inflammatory Drug Use in Postoperative Pain Management. The American Surgeon. Nov 25:0003134820952834.

Choi GJ, Kang H, Baek CW, Jung YH, Kim DR(2015). Effect of intraperitoneal local anesthetic on pain characteristics after laparoscopic cholecystectomy. World journal of gastroenterology.

Dec
Cianci P, Tartaglia N, Fersini A, Dario C, Rocco P, Rosaria M,et al .(2020). Pain control after laparoscopic cholecystectomy. Ann ItalChir. 2020 Feb;91(6):611-6.

Ebrahimifard F, Nooraei N.(2013) Postoperative pain after laparoscopic cholecystectomy: a randomized clinical trial comparing intraperitoneal bupivacaine versus intravenous pethidine. Surgical Laparoscopy Endoscopy \& Percutaneous Techniques. Feb 1;23(1):88-92.

Fokunang C, Fokunang ET, Frederick K, Ngameni B, Ngadjui B.(2018). Overview of non-steroidal anti-inflammatory drugs (nsaids) in resource limited countries. Moj Toxicol.;4(1):5-13.

Honca M, Kose EA, Bulus H, Horasanh E.(2014) The postoperative analgesic efficacy of intraperitoneal bupivacaine compared with levobupivacaine in laparoscopic cholecystectomy.

ActaChirurgicaBelgica. Jan 1;114(3):174-8.

Khan MR, Raza R, Zafar SN, Shamim F, Raza SA, Pal KM, et al (2012). Intraperitoneal lignocaine (lidocaine) versus bupivacaine after laparoscopic cholecystectomy: results of a randomized controlled trial. journal of surgical research. Dec 1;178(2):662-9.

Li J, Wang G, Xu W, Ding M, Yu W.(2018). Efficacy of intravenous lidocaine on pain relief in patients undergoing laparoscopic cholecystectomy: a meta-analysis from randomized controlled trials. International Journal of Surgery. 2018 Feb 1;50:137-45.

Mitra S, Khandelwal P, Roberts K, Kumar S, Vadivelu N.(2012) Pain relief in laparoscopic 
cholecystectomy - a review of the current options. Pain Practice. Jul;12(6):485-96.

Mumba JM, Kabambi FK, Ngaka CT.(2017) Pharmacology of local anaesthetics and commonly used recipes in clinical practice. InCurrent topics in anesthesiology Feb 8 . IntechOpen.

Nielsen RV. (2018)Adjuvant analgesics for spine surgery. Danish medical journal. Mar 1;65(3).

Pierre S, Whelan R.(2013) Nausea and vomiting after surgery. Continuing Education in Anaesthesia, Critical Care \& Pain. 2013 Feb 1;13(1):28-32.

Protic M, Veljkovic R, Bilchik AJ, Popovic A, Kresoja M, Nissan A,et al (2017). A. Prospective randomized controlled trial comparing standard analgesia with combined intraoperative cystic plate and port-site local anesthesia for post-operative pain management in elective laparoscopic cholecystectomy. Surgical endoscopy. Feb;31(2):704-13.

Roberts KJ, Gilmour J, Pande R, Nightingale $P$, Tan LC, Khan S. (2011).Efficacy of intraperitoneal local anaesthetic techniques during laparoscopic cholecystectomy. Surgical endoscopy. Nov;25(11):3698705.

Tremont-Lukats IW, Challapalli V, McNicol ED, Lau J, Carr DB.(2005). Systemic administration of local anesthetics to relieve neuropathic pain: a systematic review and meta-analysis. Anesthesia \& Analgesia. Dec 1;101(6):1738-49.

Tulgar S, Kapakli MS, Senturk O, Selvi O, Serifsoy TE, Ozer Z.(2018) Evaluation of ultrasound-guided erector spinae plane block for postoperative analgesia in laparoscopic cholecystectomy: a prospective, randomized, controlled clinical trial. Journal of clinical anesthesia. Sep 1;49:101-6.
White PF.(2005) The changing role of non-opioid analgesic techniques in the management of postoperative pain. Anesthesia \& Analgesia. Nov 1;101(5S):S5-22.

Yang SY, Kang H, Choi GJ, Shin HY, Baek CW, Jung YH,et al.(2014). Choi YS. Efficacy of intraperitoneal and intravenous lidocaine on pain relief after laparoscopic cholecystectomy. Journal of International Medical Research. Apr;42(2):307-19.

Yousefshahi F, Predescu O, Asenjo JF.(2017) The efficacy of systemic lidocaine in the management of chronic pain: A literature review. Anesthesiology and pain medicine. Jun;7(3).

Zhang Z, Xu H, Zhang Y, Li W, Yang Y, Han T, et al. (2017). Nonsteroidal anti-inflammatory drugs for postoperative pain control after lumbar spine surgery: a meta-analysis of randomized controlled trials. Journal of clinical anesthesia. Dec 1;43:84-9. 